\title{
A retrospective analysis of maternal deaths over a period of five years at a tertiary care hospital of central India
}

\author{
Kalpana Yadav, Neelu Rajput*, Arti Tiwari, Gunjan Yadav
}

Department of Obstetrics and Gynecology, Shyam Shah Medical College, Rewa, Madhya Pradesh, India

Received: 07 September 2018

Accepted: 05 October 2018

\section{*Correspondence:}

Dr. Neelu Rajput,

E-mail: sahab.yadav1987@gmail.com

Copyright: () the author(s), publisher and licensee Medip Academy. This is an open-access article distributed under the terms of the Creative Commons Attribution Non-Commercial License, which permits unrestricted non-commercial use, distribution, and reproduction in any medium, provided the original work is properly cited.

\begin{abstract}
Background: Maternal mortality is one of the important indicators used for the measurement of maternal health. The present study was conducted to analyse the maternal deaths over a period of five years in a tertiary care centre, GMH Rewa, Madhya Pradesh.

Methods: A retrospective observational study was conducted in department of Obstetrics and Gynaecology, Shyam Shah Medical College and associated Gandhi Memorial Hospital, Rewa. The case records of all maternal deaths between January 3013 to December 2017 were collected from hospital medical records and studied. Data were analyzed statistically.

Results: There were 214 maternal deaths from January 3013 to December 2017.The average maternal mortality ratio over a period of five years was $\mathbf{4 7 1 . 5}$ per one lac live births. Majority of maternal deaths were from toxaemia $33.2 \%$, haemorrhage $26.2 \%$, anaemia $16.3 \%$ and sepsis $12.6 \%$.

Conclusions: The present study highlights the importance of early antenatal registration of all pregnancies and regular follow up of cases by trained staff. Active management of high-risk groups by frequent antenatal visits, fluid and component transfusions, aggressive management of infection and closer monitoring of women in labor. Higher fertility and unwanted pregnancies should be reduced through family welfare services and easy availability of Medical termination of pregnancy services to be ensured. Analysis of every maternal death through maternal death audit should be carried out.
\end{abstract}

Keywords: Haemorrhage, MMR (maternal mortality ratio), Maternal mortality, Toxemia.

\section{INTRODUCTION}

Maternal mortality is one of the important indicators used for the measurement of maternal health. Improvement of maternal health is one of the millennium development goals, MDG 5 with target $5 \mathrm{~A}$ that calls for the reduction of maternal mortality ratio by three quarters $(75 \%)$ between 1990 and 2015. ${ }^{1-2}$ According to WHO, maternal death is defined as death of a women while pregnant or within 42 days of termination of pregnancy irrespective of duration and site of pregnancy from any cause related to or aggravated by the pregnancy except accidental or incidental causes. ${ }^{3}$ Maternal mortality ratio (MMR) in
India has declined from 301 in 2001 and 167 in 20112013 to 130 in $2014-2016 .^{4-5}$ India is signatory to millennium declaration as well as sustainable developmental goals and is committed to achieving the targets of sustainable developmental goals of reducing MMR to 70 per one lac live birth by $2030 .{ }^{6}$ The present study was conducted to analyse the maternal death in rural tertiary care centre, GMH Rewa, Madhya Pradesh.

\section{METHODS}

A retrospective observational study was conducted in department of Obstetrics and Gynaecology, Shyam Shah 
Medical College and associated Gandhi Memorial Hospital, Rewa. This study was conducted after taking permission from the hospital administrators and after the approval from institutional Ethical committee. The present study was retrospective study. This study was conducted between January 3013 to December 2017.

The case record files of all maternal deaths i.e. death of a women while pregnant or within 42 days of termination of pregnancy irrespective of the duration and site of pregnancy were collected from hospital medical records and studied.

All the data regarding whether the women was registered/unregistered, age, parity, rural/urban details, referral/arrival from home, education status, gestational age, mode of delivery, admission death interval and causes of death were critically analyzed with a view to find out the factors associated and contributing to maternal deaths.

All the maternal deaths due to complications during pregnancy are included in this study. Those women who died from accidental and incidental causes were not included in the study.

Maternal mortality rate is expressed as number of maternal deaths per 1,00,000 total births. Wherever there was more than one contributory cause, main cause of death was recorded. Attempts are made to identify avoidable factors. In this study, main emphasis way given to direct obstetric death along with indirect cause of death and at what level that was preventable.

\section{RESULTS}

During this study period there were total 214 maternal deaths and 45358 live births.In present study, MMR for the year 2013,2014,2015,2016 and 2017 was $352.2,398.8,522.3,534.5$ and 528.8 per one lac live birth respectively.

The average maternal mortality ratio over a period of five years was 471.5 per one lac live births (Table 1 ).

Table 1: Year wise distribution of maternal mortality.

\begin{tabular}{|llll|}
\hline Year & Maternal death & $\begin{array}{l}\text { Live birth } \\
\text { MNR (per } \\
\text { one lac birth) }\end{array}$ \\
\hline 2013 & 29 & 8234 & 352.2 \\
\hline 2014 & 35 & 8777 & 398.8 \\
\hline 2015 & 47 & 8999 & 522.3 \\
\hline 2016 & 51 & 9541 & 534.5 \\
\hline 2017 & 52 & 9834 & 528.8 \\
\hline Total & 214 & 45385 & 471.5 \\
\hline
\end{tabular}

Maximum number of maternal deaths were in the age group of $20-25$ years $(65.4 \%)$ followed by $25.2 \%$ in the age group of 26-30 years (Table 2).
Table 2: Distribution according to age group.

\begin{tabular}{|ll|}
\hline Age group (Years) & Number (Percentage) \\
\hline$<19$ years & $6(2.8 \%)$ \\
\hline $20-25$ & $140(65.4 \%)$ \\
\hline $26-30$ & $54(25.2 \%)$ \\
\hline $31-35$ & $11(5.1 \%)$ \\
\hline$>35$ & $3(1.4 \%)$ \\
\hline
\end{tabular}

$56.1 \%$ of maternal deaths were reported in multigravida and $43.9 \%$ of maternal deaths cases were occur in primigravida (Table 3 ).

Table 3: Distribution according to parity.

\begin{tabular}{|lc|}
\hline Parity & Number (Percentage) \\
\hline Primi & $94(43.9 \%)$ \\
\hline Multi & $120(56.1 \%)$ \\
\hline
\end{tabular}

There were $70.6 \%$ maternal deaths in unbooked women and $29.4 \%$ maternal deaths in booked women (Table 4).

Table 4: Distribution according to booking status.

\begin{tabular}{|lc|}
\hline Status & Number (Percentage) \\
\hline Booked & $63(29.4 \%)$ \\
\hline Unbooked & $151(70.6 \%)$ \\
\hline
\end{tabular}

$136(63.6 \%)$ of maternal deaths were in the postpartum period, whereas $50(23.4 \%)$ of patients were undelivered. $7.9 \%$ of maternal deaths occur during intranatal period.Out of all maternal deaths, 101 (47.2\%) patients delivered vaginally, while $22(10.3 \%)$ patients underwent caesarean section, while $13(6.1 \%)$ patients underwent exploratory laparotomy for rupture uterus and ectopic pregnancy (Table 5).

Table 5: Distribution according to mode of delivery.

\begin{tabular}{|ll|}
\hline Mode of delivery & Number (Percentage) \\
\hline Antenatal (undelivered) & $50(23.4)$ \\
\hline Intranatal & $17(7.9)$ \\
\hline Postnatal-vaginal & $101(47.2)$ \\
\hline Postnatal-LSCS & $22(10.3)$ \\
\hline Postnatal-Exp Lap. & $13(6.1)$ \\
\hline Early pregnancy death & $11(5.1)$ \\
\hline Total death & 214 \\
\hline
\end{tabular}

There were $107(50 \%)$ patients died within 24 hours, among them 44 patients died within 6 hours. 42(19.6\%) patients died within next 24 hours and another $24(11.2 \%)$ patients died within 48-72 hours. 41(19.2\%) patients died after 72 hours (Table 6).

Direct obstetric deaths occurred in $76.2 \%(163 / 214)$ and in $23.8 \%(51 / 214)$ deaths occur due to indirect obstetric causes. Direct obstetric deaths include deaths from haemorrhage $26.2 \%(56 / 214)$, toxemia $33.2 \%$ (71/214), sepsis $12.6 \%(27 / 214)$ and embolism $4.2 \%$ (9/214). 
Indirect obstetric deaths occurred in $23.8 \%(51 / 214)$ women and included deaths due to anaemia $16.3 \%$ $(35 / 214)$, jaundice $1.9 \%(4 / 214)$, malaria $0.2 \%$, typhoid $0.2 \%$, heart disease $1.9 \%$, BT reaction $1.4 \%$ and high spinal anaesthesia $0.5 \%$ (Table 7).

Table 6: Distribution according to admission: death interval.

\begin{tabular}{|c|c|c|}
\hline \multicolumn{2}{|c|}{$\begin{array}{l}\text { Admission-death interval } \\
\text { (hours) }\end{array}$} & Number (Percentage) \\
\hline \multirow{3}{*}{$<24$} & $1-6$ & $44(20.6)$ \\
\hline & $6-12$ & $27(12.6)$ \\
\hline & $12-24$ & $36(16.8)$ \\
\hline \multicolumn{2}{|c|}{$24-48$} & $42(19.6)$ \\
\hline \multicolumn{2}{|c|}{$48-72$} & $24(11.2)$ \\
\hline \multicolumn{2}{|c|}{$>72$} & $41(19.2)$ \\
\hline
\end{tabular}

Table 7. Causes of maternal mortality.

\begin{tabular}{|l|l|}
\hline Direct causes (163) & Number (Percentage) \\
\hline Haemorrhage & $56(26.2 \%)$ \\
\hline Toxemia & $71(33.2 \%)$ \\
\hline Sepsis & $27(12.6 \%)$ \\
\hline Pulmonary embolism & $9(4.2 \%)$ \\
\hline Indirect causes (51) & \\
\hline Anaemia & $35(16.3 \%)$ \\
\hline Jaundice & $4(1.9 \%)$ \\
\hline Malaria & $2(0.9 \%)$ \\
\hline Typhoid & $2(0.9 \%)$ \\
\hline Heart disease & $4(1.9 \%)$ \\
\hline BT reaction & $3(1.4 \%)$ \\
\hline High spinal anaesthesia & $1(0.5 \%)$ \\
\hline Total & 214 \\
\hline
\end{tabular}

\section{DISCUSSION}

In present study, MMR for the year 2013, 2014, 2015, 2016 and 2017 was 352.2, 398.8, 522.3, 534.5 and 528.8 per one lac live birth respectively. The average maternal mortality ratio over a period of five years was 471.5 per one lac live births. Various studies have shown a wide variation in MMR.

In this study, MMR gradually constant in recent past year might be due to effect of Janani Suraksha Yojana (JSY), under NRHM, which on one side has tried to promote institutional deliveries to avert maternal deaths, on other hand maximally unbooked complicated patients reaches hospital in moribund state, without any antenatal visit. As transport facilities improved in recent years, so patients reported hospital in state, in which they can be saved but still it has to improve much more.

Maximum number of maternal deaths were in age group between 20-30 years because most of admitted women belong to this age group. Similarly, Uma Devi $\mathrm{S}$ et al and Nelissen et al study consistent with our present study. Maximum maternal deaths were reported in multigravida
$(56.1 \%))^{7,8}$ Most of maternal deaths cases were unbooked (70.6\%). Similarly, Nelissen et al found $50 \%$ deaths in multipara and Kapadia LD et al reported $76 \%$ deaths in unbooked cases. ${ }^{8,9}$ Both study results were almost similar to our present study. Very high percentage of unbooked patients in maternal deaths highlight the importance of adequate antenatal care. It depicts the inability of utilization of available health care facilities by majority of local population. There were $136(63.6 \%)$ cases of maternal deaths were in the postpartum period, whereas $50(23.4 \%)$ of patients were undelivered. $7.9 \%$ of maternal deaths occur during intranatal period. Khumanthem PD et al in their study reported postpartum death in about $70 \%$ cases, nearly similar to our present study. ${ }^{10}$ Out of all maternal deaths, $101(47.2 \%)$ patients delivered vaginally, while $22(10.3 \%)$ patients underwent caesarean section, while $13(6.1 \%)$ patients underwent exploratory laparotomy for rupture uterus and ectopic pregnancy.

It was found that $50 \%$ of deaths occurred within 24 hours, out of them most were died within 6 hours, possibly due to most women referred in moribund state. May be because this patient which were earlier died at home and were not registered. Now, they are dying at institution. Nawal M.et al studies are consistent with our present study. ${ }^{11}$ Another $19.6 \%$ deaths occur within 48 hours. This is possibly due to poor general condition of women on admission, late referrals and at times due to a long travel time from neighboring districts. Deaths due to anaemia and sepsis along with haemorrhage, DIC, anaesthesia difficulties/complications and nonavailability of ICU bed are considered preventable causes account for $30.4 \%$ of total death.

Direct obstetric deaths occurred in $76.2 \%$ (163/214) cases. Direct obstetric deaths include deaths from haemorrhage $26.2 \%$, toxemia $33.2 \%$, sepsis $12.6 \%$ and embolism $4.2 \%$. Haemorrhage accounted for $26.2 \%$ $(56 / 214)$ of all maternal death. Roopa PS et al reported $17.4 \%$ of maternal death due to haemorrhage in their study. ${ }^{12}$

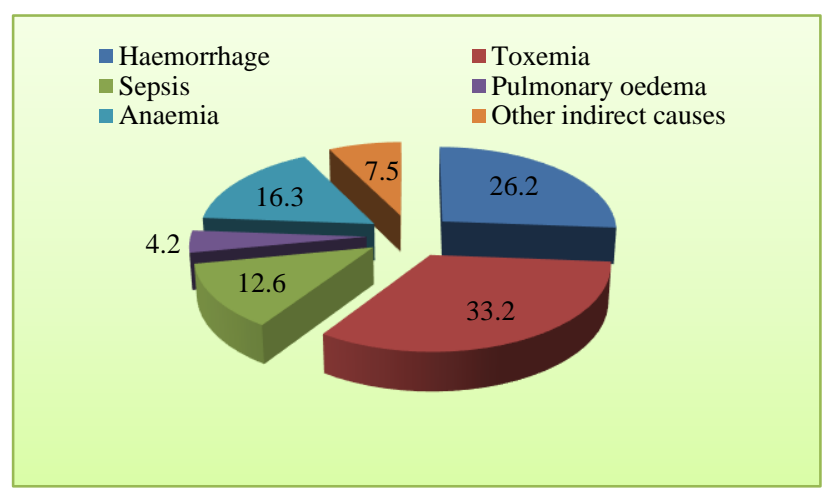

Figure 1: Causes of maternal mortality

This study results were slightly lower than our present study. Haemorrhage accounted for $34.3 \%$ (56/163) of 
direct obstetric deaths and included of deaths $58.9 \%$ $(33 / 56)$ by primary PPH, $17.8 \%(10 / 56)$ by obstructed labour, $7.1 \%(4 / 56)$ rupture uterus, $10.7 \%(6 / 56)$ by placenta previa, $3.6 \%(2 / 56)$ by vesicular mole and $1.8 \%$ $(1 / 56)$ by ectopic pregnancy. The provision of timely blood transfusion can save lives at risk due to severe haemorrhage. The availability of blood banks at all first referral units (FRUs) and their proper functioning are needed. Toxemia cases accounted for $33.2 \%(71 / 214)$ of all maternal deaths and included $28.2 \%$ (20/71) preeclampsia and $71.8 \%$ (51/71) eclampsia cases. Almerie et al in their study found $13.3 \%$ of maternal death and Oladapo et al found $22.7 \%$ of maternal death in toxaemia cases. ${ }^{13,14}$ Incidence was higher in our present study than other studies due to early identification of sign and symptoms of eclampsia in peripheral area by trained staff and use of loading dose of $\mathrm{MgSO}_{4}$ in recent years. Maximum mortality were seen in complicated cases of eclampsia associated with pulmonary oedema, DIC, acute renal failure, intracranial haemorrhage. Sepsis seen in $12.6 \%(27 / 214)$ of all maternal death. Sepsis cases account for $16.6 \%(27 / 163)$ of direct cause of death. Sepsis cases included puerperal $81.5 \%$ (22/27) and $18.5 \%$ $(5 / 27)$ post abortion. Incidence of sepsis were decreased over the years due to use of higher antibiotics, early detection of infections, banning of illegal abortions and improved standard of care because of ICU facility.

Indirect causes of death accounted for $23.8 \%$ cases of maternal deaths. Anaemia, jaundice and heart disease were responsible for $16.3 \%, 1.9 \%$ and $1.9 \%$ of cases of indirect maternal deaths respectively. Anaemia constitutes majority cases. Anaemia is a preventable disease and measures should be taken to improve nutritional status in pre-conceptional period and antenatal period. Preexisting anaemia worsens as pregnancy advances leading to heart failure and death. It also impedes the mother ability to resist infection or cope with haemorrhage and increases the likelihood of her dying in childbirth. ${ }^{15}$ Jaundice is the second leading indirect cause of maternal mortality. Infections due to malaria and typhoid were responsible for $0.2 \%$ of cases of maternal deaths each.

\section{CONCLUSION}

The classical triad of causes of maternal mortality in present study remained haemorrhage, toxemia and sepsis. In this study incidence of toxemia is higher than haemorrhage. The present study highlights the importance of early antenatal registration of all pregnancies and regular follow up of cases by trained staff. Poor nutritional status, lack of antenatal care, unawareness of warning signs of pregnancy, unsupervised dai handled deliveries, social bias towards blood donation and late referrals are the major contributory factors leading to poor maternal prognosis. There should be active management of high-risk groups by frequent antenatal visits, direct consultant supervision, liberal use of cardiotocography, biochemical markers, fluid and component transfusions, aggressive management of infection and closer monitoring of women in labor. Higher fertility and unwanted pregnancies should be reduced through family welfare services and easy availability of Medical termination of pregnancy services to be ensured. Analysis of every maternal death through maternal death audit, either at community level (verbal autopsy) or at the institutional level should be carried out. Vigorous mass campaign for community based maternal education programme should be the top priority of maternal and child health programs.

Funding: No funding sources

Conflict of interest: None declared

Ethical approval: The study was approved by the Institutional Ethics Committee

\section{REFERENCES}

1. WHO. World Health Statistics 2014.Fact Sheets. Geneva: World Health Organization; 2009 and 2014. Available at http://apps.who.int/iris/ bitstream/10665/112738/1/9789240692671_eng.pdf

2. National Technical Group (NTG), NHM (MOHFW) GOI. 2013-14. Available at https://mohfw.gov.in/aboutus/departments/departme nts-health-and-family-welfare/principal-accountsoffice/financial-year-2013-14.

3. World Health Organization. International statistical classification of diseases and related health problems. Available at http://www.who.int/classifications/icd/en

4. Sample Registration System Bulletin 2014. Office of the Registrar General. Ministry of Home Affairs, Government of India. Available from: http://www.censusindia.gov.in/vital_statistics/SRS_ Bulletins/SRS_Bulletins-September_2014.pdf.

5. Government of India. Ministry of Health and Family Welfare. Family Welfare Statistics in India.2011:11.

6. UN Sustainable Development Goals Available at http://www.un.org/sustainabledevelopment/health/

7. Uma Devi S, Ayesha S, Radha S, Nair ATS, Sulochana KD. Burden and causes of maternal mortality and near miss in a tertiary care centre of Kerala, India. Int J Reprod Contracept Obstet Gynecol. 2017;6(3):807-13.

8. Nelissen EJ, Mduma E, Ersdal HL, Evjen-Olsen B, van Roosmalen JJ, Stekelenburg J. Maternal near miss and mortality in a rural referral hospital in northern Tanzania: a cross-sectional study. BMC Preg Childbirth. 2013;13(1):141.

9. Kapadia LD, Lamba AR. Maternal mortality: a tertiary centre panic. Int J Reprod Contracept Obstet Gynecol. 2017;6(8):3256-9.

10. Khumanthem PD, Chanan MS, Samjetshabam RD. Maternal mortality and it's causes in a tertiary centre: J Obstet Gynecol India. 2012;62(2):168-71.

11. Nawal M. Nour, MD, MPH, An Introduction to maternal Mortality. Rev Obstet Gynecol. 2008;1(2):77-81. 
12. PS R, Verma S, Rai L, Kumar P, Pai MV, Shetty J. "Near Miss" Obstetric Events and Maternal Deaths in a tertiary Care Hospital: Aud J Preg. 2013;2013.

13. Almerie Y, Almerie MQ, Matar HE, Shahrour Y, Al Chamat AA, Abdulsalam A. Obstetric near-miss and maternal mortality in maternity university hospital, Damascus, Syria: a retrospective study. BMC Preg. Childbirth. 2010;10(1):65.

14. Olufemi T Oladapo1, Adewale O Sule-Odul, Adetola O Olatunjil and Olusoji J Daniel2. "Near-miss" obstetric events and maternal deaths in Sagamu, Nigeria: a retrospective study. Reproductive Health 2005,2(1):9.
15. Bedi N, Kambo I, Dhillon BS, et al. Maternal deaths in India: preventable tragedies. (An ICMR Task Force Study). J Obstet Gynecol India. 2001;51:8692.

Cite this article as: Yadav K, Rajput N, Tiwari A, Yadav G. A retrospective analysis of maternal deaths over a period of five years at a tertiary care hospital of central India. Int J Reprod Contracept Obstet Gynecol 2018;7:4657-61. 